\title{
Spatial and Temporal Variation in Abundance of Anopheles (Diptera: Culicidae) in a Malaria Endemic Area in Papua New Guinea
}

\author{
J.L.K. HII,${ }^{1,2}$ T. SMITH,,${ }^{1,3}$ A. MAI, ${ }^{1}$ S. MELLOR, ${ }^{1}$ D. LEWIS, ${ }^{1,4}$ N. ALEXANDER, ${ }^{1}$ \\ AND M. P. ALPERS ${ }^{1}$
}

\begin{abstract}
J. Med. Entomol. 34(2): 193-205 (1997)
ABSTRACT Abundance of anophelines in 10 villages in the Wosera area of Papua New Guinea was monitored during 1990-1993. Of 85,197 anophelines collected in 1,276 paired indoor and outdoor landing catches, $40.4 \%$ were Anopheles koliensis Owen, 36.7\% An. punctulatus Donitz, 14.3\% An. karvari (James), 4.9\% An. farauti s.l. Laveran, 3.1\% An. longirostris Brug, and $0.7 \%$ An. bancroftii Giles. Maps of average indoor biting rates were produced using a Bayesian conditional autoregressive model which allowed for heterogeneities in sampling effort over time and space. Differences in spatial distributions among species were observed among and within villages and were related to the distribution of larval habitats and vegetation. Abundance of An. punctulatus and An. koliensis decreased with distance from the main waterway and probably from a sago swamp forest at 6 villages in North Wosera. Abundance of An. punctulatus was associated negatively with those of An. farauti s.l., An. longirostris, and An. bancroftii. The latter 3 species also had relatively low ratios of indoor-to-outdoor biting rates, and earlier biting times than An. punctulatus. Human blood indices of at least 0.79 were observed for all species except An. bancroftii. Abundance of all 6 species was correlated temporally with recent rainfall, but An. koliensis, An. karvari, and An. longirostris showed greater temporal variability than the other species. An. punctulatus and An. koliensis tended to occur together in time and space (index of association, $I=0.85$ ). Weaker associations were seen between An. farauti s.l. and An. longirostris $(I=0.44)$ and An. koliensis and An. karvari $(I=0.34)$. The most frequently collected species occurred together and were concentrated near the Amugu river; the remaining species tended to occur together but in different parts of the Wosera area. The importance of understanding ecological requirements of the different Anopheles vectors and their association with key household and landscape features are discussed in relation to malaria transmission and control.
\end{abstract}

KEY WORDS Anopheles spp., ecology, biting cycles, conditional autoregressive model, spatial analysis, malaria

MALARIA OCCURS THROUGHOUT the coastal lowlands of Papua New Guinea but has been most intensively studied in Madang and East Sepik Provinces near the north coast. The Madang area is highly endemic for both Plasmodium falciparum and $P$. vivax (Cattani et al. 1986a). In the Wosera area of East Sepik province, P. malariae also is frequently encountered (Genton et al. 1995). Extensive entomological studies in preparation for malaria vaccine trials have been carried out near Madang (Burkot et al. 1987, 1988b). The Wosera area also has been the site of recent epidemiolog-

IPapua New Guinea Institute of Medical Research, P.O. Box 378, Madang, Papua New Guinea.

'Department of Public Health and Tropical Medicine, James Cook University, Townsville, Queensland 4811, Australia.

${ }^{3}$ Current address: Department of Public Health and Epidemiology, Swiss Tropical Institute, Socinstrasse 57, Postfach CH-4002, Basel, Switzerland.

${ }^{4}$ Southern Zone Population Health Unit, Brisbane, Queensland, Australia. ical studies in preparation for vaccine trials (Alpers et al. 1992, Genton et al. 1995), but the ecology of Anopheles spp. has not been studied since a pilot DDT trial during 1958-1959 (Peters 1960a, b; Peters and Standfast 1960).

The anopheline situation in Papua New Guinea is complex, both taxonomically and ecologically. The main vectors are members of the Anopheles punctulatus complex. Recent allozyme studies have shown that there are at least 6 species within this group in Papua New Guinea (Foley et al. 1993), including An. punctulatus s.s. Donitz, An. koliensis Owen, and 4 sibling species of An. farauti Laveran s.l. The 2 former species and at least 1 member of the An. farauti complex are important malaria vectors in Papua New Guinea (Burkot et al. 1988b). Two more species with distributions centering around New Guinea have been considered to be minor vectors-de Rook (1929) and Metselaar (1957) found low infection rates in An. 
bancroftii Giles, and An. longirostris Brug was suspected to be a minor vector by Peters (1965). The latter species feeds predominantly on pigs (Charlwood et al. 1985) in the Madang area, but there may be several sibling species (D.H. Foley, personal communication) with different ecologies. In addition, An. karwari and An. subpictus, 2 secondary malaria vectors whose distribution centers on the Indian subcontinent, have been found locally in Papua New Guinea (Peters and Christian 1963, Lee et al. 1987).

Variation in vector ecology is one of the most important factors affecting heterogeneity in the microepidemiology of malaria (Greenwood 1989). Both in the Western Province of Papua New Guinea (Nakazawa et al. 1994), and near Madang (Burkot et al. 1987, 1988b; Cattani et al. 1986b; Charlwood et al. 1983, 1986), considerable spatial variation in levels of malaria endemicity, transmission rates, and mosquito abundance and survival rates have been found, even between villages within a few kilometers of each other. The known malaria vectors near Madang are An. punctulatus, An. koliensis, and An. farauti No. 1. The latter is 1 of the 6 sibling species within the An. farauti complex and has been given the non-Linnean designation (Foley et al. 1993). An. punctulatus larvae occur in small sunlit bodies of water and are distributed widely around Madang (Charlwood et al. 1986), whereas An. koliensis breeds in semipermanent habitats at forest margins (Belkin 1962) and has a more focal distribution (Charlwood et al. 1986). An. farauti No. 1 favors brackish water and streams in lowland coastal areas.

Rainfall is spread relatively evenly throughout the year in most of Papua New Guinea, so that there is no season without any mosquitoes and densities can reach very high levels (Spencer 1970, Affifi et al. 1980). However, patterns of seasonality differ among mosquito species (Burkot et al. $1988 \mathrm{~b}$ ), and this may be important in the epidemiology of malaria because of the interspecific variation in transmission potential. For instance, in the Madang area, the peak abundance of An. farauti No. 1 occurs at the end of the dry season, when the larvae are less likely to be flushed out of riparian breeding sites (Charlwood et al. 1986).

Small-area variations in contact rates between mosquitoes and man may have a profound effect on the true vector potential of a mosquito population (Dye and Hasibeder 1986) and on the immunological responses in the host population (Forsyth et al. 1989). Limited mixing of mosquito populations between villages also tends to perpetuate heterogeneities in transmission of plasmodial parasites (Charlwood et al. 1988).

Tto determine whether the pattern of small-area variation near Madang was reproduced elsewhere in Papua New Guinea, we studied the extent and scale of spatial and temporal heterogeneity in the anopheline populations in the Wosera area. Peters and Standfast (1960) found that An. punctulatus was the primary vector throughout the year, with lower densities of An farauti s.l. and An. koliensis, but did not carry out detailed studies of small-area variation. Using a Bayesian model of spatial and temporal variability developed in analyses of malaria vectors in Tanzania (Smith et al. 1995), we estimated how abundance of An. punctulatus complex mosquitoes and 3 other anophelines varied geographically during a 34-mo period in 10 Wosera villages. We then attempted to relate the different spatial and temporal patterns observed for different anophelines to their ecology and to consider the implications for malaria transmission.

\section{Materials and Methods}

Study Site. The study was carried out as part of the Papua New Guinea Malaria Vaccine Epidemiology and Evaluation Project (Alpers et al. 1992) in the Wosera area $\left(143^{\circ} \mathrm{E}, 52^{\prime} \mathrm{S}\right)$ of East Sepik Province (Fig. 1). The area is divided into 2 census divisions, North and South Wosera, comprising 469 and $333 \mathrm{~km}^{2}$, respectively. Its major feature is the Amugu (Screw) River, a permanent stream of greatly variable discharge arising in mountains to the north. The altitude is $\approx 180 \mathrm{~m}$ above sea level. The climate is wet tropical (Genton et al. 1995) with a mean annual rainfall of $1,847 \mathrm{~mm}$ during 1990-1993 (range, 1,759-1,936 mm). Approximately $58-65 \%$ of annual precipitation falls during the wet season (October-April); the dry season occurs from May to September.

All villages and hamlets were accessible by dirt roads and footpaths. Village populations ranged from 100 to 800 residents and were subdivided into geographically distinct hamlets. Traditional Wosera houses consist of a timber frame (inverted V) covered with sago leaf roofs that reach the ground. More recently, houses with elevated floors, corrugated iron roofing, and walls of split bamboo or sago palm stems have appeared.

House positions were recorded using a handheld global positioning system (GPS) device (Trimble Navigational Europe, London). The resulting map was validated against sketch maps of the village. The heights of houses and other architectural features also were recorded in annual surveys of the village. The software system MapInfo (MapInfo 1990) was used to compile a digitized map using the coordinates collected with the GPS system, showing the houses sampled, roads, rivers, creeks, potential Anopheles breeding sites, and other landscape features. Numerous seasonal streams exist throughout the area and their flow corresponds with periods of heavy rainfall, usually from October through April. The central part of the study area consisted of the flood plain of the Screw River and its tributaries (Fig. 2). Most of the land is mixed regrowth with patches of sago palm, Metroxylon sagu, swamp (Haanjens et al. 1968). Allen et al. (1993) distinguished 2 agricultural systems in use. Apusit, Kunjinigini-1, Nindi- 


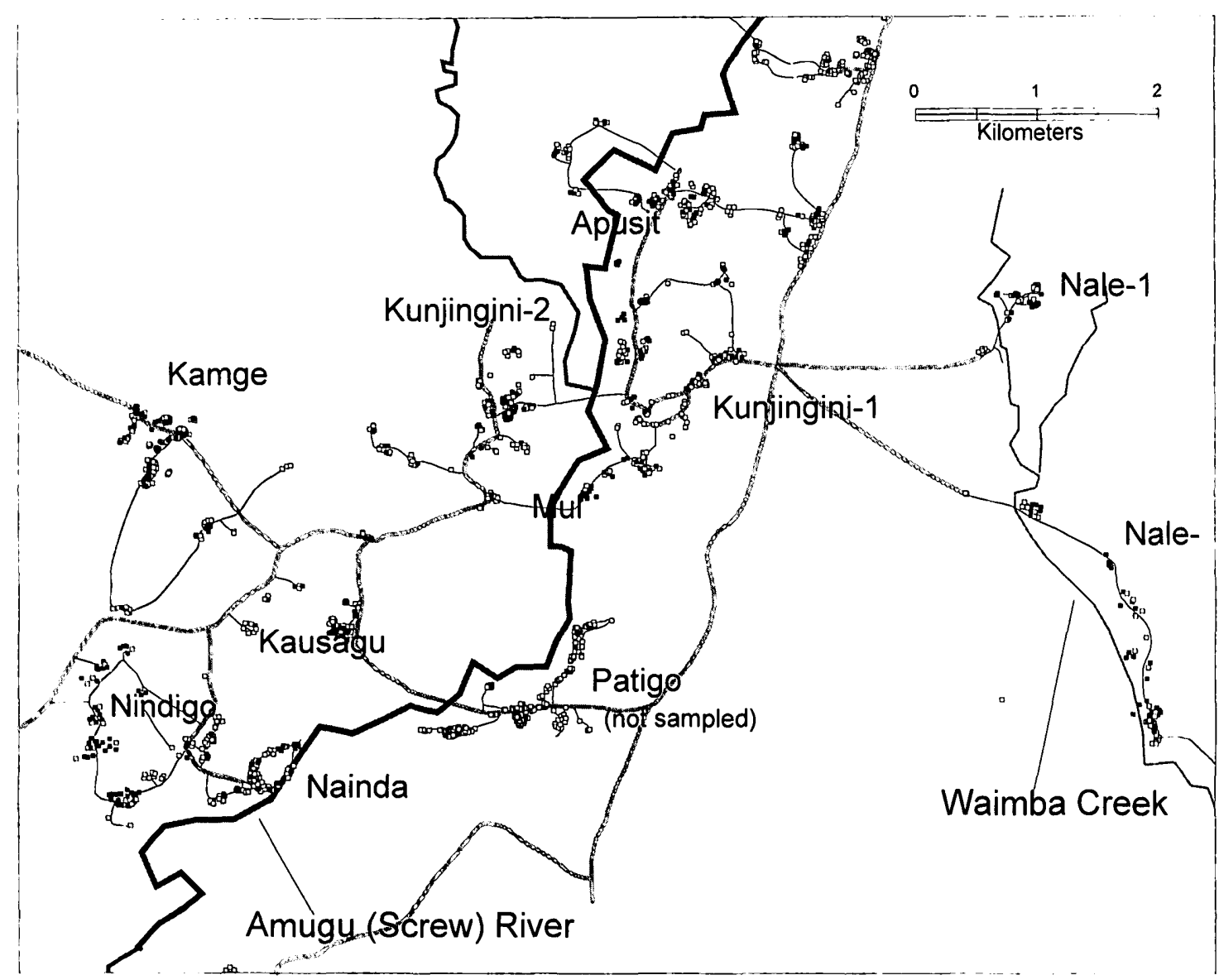

Fig. 1. Map of Wosera area, showing sampled (filled boxes) and unsampled (open boxes) houses, all-weather roads $(===)$, footpaths $(\longrightarrow)$, Amugu (Screw) River, and Waimba creek.

go, Kausagu, and Nainda form part of the most intensively cultivated area in East Sepik Province and depend on silt from river floods to sustain fertility with a short fallow period. Yams, Dioscorea esculenta, were the most important crop, but planted sago and taro, Colocasia esculenta, also are important. In Mul, Kunjingini-2, and Kamge, where there is less silt from river flooding, land use is less intensive, with a longer period of regrowth.

Much of Nale village (comprising Nale-1 and Nale-2), which is separated from the rest of the study area by a wide plain, is dominated by $I m$ perata spp. grassland or kunai. In Nale, the forest is cultivated less intensively than in the valley of the Amugu (Screw) River, and gardens extend into the neighboring grasslands.

Sampling of Anophelines. In June 1990, 7 villages (Apusit, Kunjingini-1, Nale-1, Nale-2, Kunjingini-2, Mul, Kamge) in North Wosera and 3 villages (Kausagu, Nindigo, Nainda) in South Wosera were selected for entomological monitoring. Sampling of Nale-2 and Mul commenced in October 1991 and February 1992, respectively; sampling of Nainda was suspended temporarily during Febru-
ary-August 1992; sampling ceased on September 1993. All-night human landing collections were made monthly in these villages by resident adults who gave informed consent after receiving consent protocols and verbal explanations in Neo-Melanesian language on the rationale and purpose of entomological monitoring, including possible hazards. Ethical guidelines of the Papua New Guinea Medical Research Council were followed. Each of the 8 villages were divided geographically into 5 sectors (A-E), whereas Kamge and Nainda were divided into 6 sectors (A-F). Within each sector, a random individual was selected each month, and the house inhabited by that individual was, where possible, sampled for mosquitoes. The different sectors were sampled on 5 consecutive nights; sectors $\mathbf{E}$ and $\mathbf{F}$ were sampled concurrently on the 5th night. Paired indoor and outdoor landing catches were made by 4 adult male collectors working in 2 teams of 2,1 team working from 1800 to 2400 hours and the other from 2400 to 0600 hours. One member of each team collected mosquitoes which landed on him inside the selected house; the 2nd collected outside. Searches for engorged resting mosquitoes were carried out from 


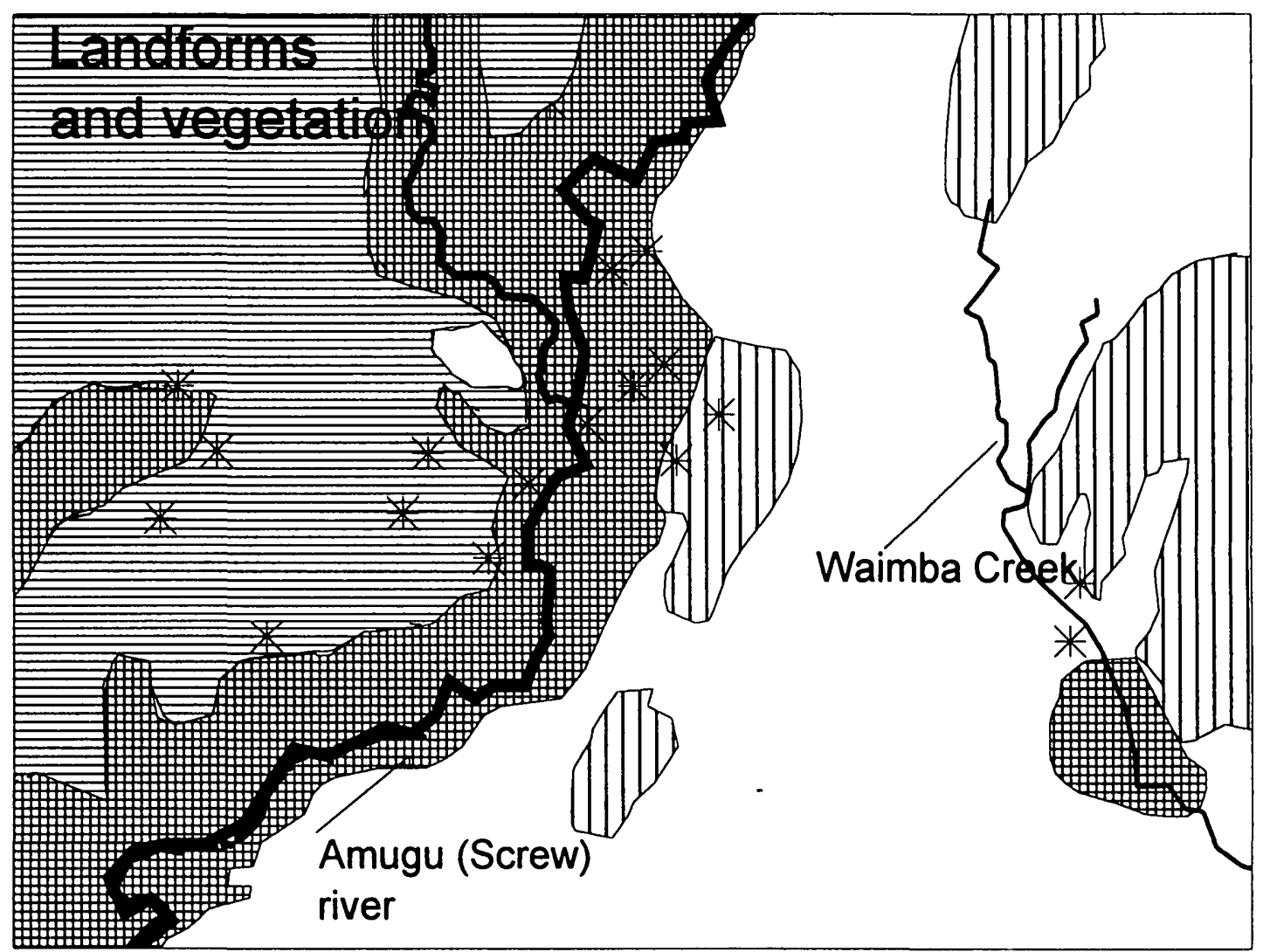

Fig. 2. Vegetation and land systems map of the Wosera area. Names for the land systems are those used by Haanjens et al. (1968) for forest and grass-covered hills with garden regrowth (曰); rolling grassland, largely Imperata spp. (ם); flat to gently undulating grassland with minor swamp vegetation ( $\square$ ); flood plains and low river terraces, with

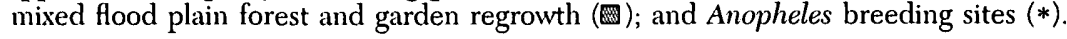

0630 to 0730 hours inside the bedrooms of the house used for the landing catch, and in 3 other neighboring houses. At the same time, outdoor collections were made from naturally occurring resting sites around the perimeters of these houses.

In the 3rd yr, immature stages of Anopheles were sought from accessible aquatic sites that could possibly serve as potential breeding places. These included rainwater surface pools, pools left by the receding streams, sago swamps, ground seepage, and surface areas in which the level of water fluctuates with that of the streams. Standard dipping using enamel bowls was used for sampling larvae from accessible sites. The approximate positions of these sites were entered into maps obtained from household surveys.

Identification of Anophelines. Mosquitoes were taken to the field laboratory, and the anophelines were identified morphologically (Belkin 1962, Lee et al. 1987). Representative females obtained from landing and resting collections were sent to the Queensland Institute of Medical Research for confirmation using cellulose acetate electrophoresis (Foley et al. 1993) and ${ }^{32} \mathrm{P}$-labeled species specific DNA probes (Cooper et al. 1991).
Human Blood Index. The midguts of semi- and fully engorged female Anopheles mosquitoes from indoor and outdoor resting collections were squashed onto filter papers and later tested by a direct enzyme-linked immunosorbent assay (ELISA) using antihost immunoglobulin (IgG) conjugates against human, pig, dog, cat, and goat (Beier et al. 1988). Each filter paper sample was eluted individually in $50 \mu \mathrm{l} \mathrm{PBS}(\mathrm{pH} 7.4)$, diluted with 1 $\mathrm{ml}$ PBS and stored at $-20^{\circ} \mathrm{C}$ until testing by direct ELISA. Cross-reactivity was decreased by the addition of 1:500 dilutions of heterologous sera to the conjugate solutions. Because $70 \%$ of the blood sources could be detected after $24 \mathrm{~h}$ of digestion (Burkot et al. 1988a), we did not compare the level of cross-reactivity with blood meals from other hosts.

Statistical Model for Spatial and Temporal Variation in Densities. Maps of average mosquito densities and estimates of day-to-day variation were produced separately for each Anopheles species, as described by Smith et al. (1995) for mapping of mosquito densities in Tanzania. In brief, a Bayesian conditional autoregressive Poisson model was used to estimate expected average indoor den- 
Table 1. Number of indoor landing catches per house, August 1990-September 1993

\begin{tabular}{|c|c|c|}
\hline \multirow{2}{*}{ No. nights } & \multicolumn{2}{|c|}{ No. houses } \\
\hline & North Wosera & South Wosera \\
\hline 1 & 201 & 78 \\
\hline 2 & 111 & 34 \\
\hline 3 & 49 & 18 \\
\hline 4 & 20 & 11 \\
\hline$>4$ & 29 & 13 \\
\hline Totals & 410 & 154 \\
\hline
\end{tabular}

sities in each house, allowing appropriately for imbalances in the sampling effort and for day-to-day variation in mosquito populations.

The (natural) logarithm of the expected number of mosquitoes ( $\mathrm{E} i j$ ) was analyzed as a function of space and time as $\ln \mathrm{E}_{i j}=\Psi_{i}+\Theta_{j}$, where $\Psi_{i}$ is the effect associated with house $i$, and $\Theta_{j}$ is the effect associated with night $j$.

To allow for spatial autocorrelation and to provide estimates of densities for houses that were not sampled, a spatially smooth function $\Psi_{x, y}$ was defined, corresponding to the mean of $\Psi_{i}$ for all houses within a radius of $150 \mathrm{~m}(r=150)$ from the point $(x, y)$, excluding any house at precisely point $(x, y)$. The model then treated the effect for a given house $i$, at position $(x, y), \Psi_{i}$, as drawn from a normal distribution with mean $\Psi_{x, y} . \Psi_{i}-\Psi_{x, y}$ then measures the difference (on a log scale) between the estimated numbers of mosquitoes in a house and the numbers that would be expected given its position.

The value of $r(150 \mathrm{~m})$ was chosen to allow for short-range autocorrelation. A lower limit to $r$ is imposed because isolated houses (with no neighbors at distances $<r$ ) cannot be included in the model. The value of $150 \mathrm{~m}$ for $r$ allowed inclusion of a total of 564 sampled houses.

The night effects, $\Theta_{j}$, also were treated as random effects. This made it possible to compare the levels of both spatial and temporal variation in densities for the different species while allowing for sampling variation (Smith et al. 1995). The model was fitted by Gibbs sampling using the program BUGS (Thomas et al. 1992).

Associations Between Species. Southwood's (1978) index of association between species was calculated as $I=2[J /(A+B)-0.5]$, where $J$ is the number of individuals of both species in samples where they occur together, and $A$ and $B$ are the total numbers of individuals of the 2 species in all samples (Service 1993). I lies between between the normal range of -1 (no association) to +1 (complete association).

\section{Results}

Sampling Pattern. Fig. 1 shows the locations of 564 houses included in the analyses and other unsampled houses. $72.7 \%(n=410)$ of the sampled houses were located in North Wosera. The distribution of houses and number of sampling occasions per house is shown in Table 1. There was a high level of household participation in implementing the original sampling plan. The number of indoor landing catches was similar during 19901991 and 1992-1993 (623 versus 653, respectively).

Species Abundance and Endophily. Morphologically identified An. koliensis, An. punctulatus, An. karwari, An. farauti s.l., An. longirostris, and An. bancroftii comprised 40.4, 36.7, 14.3, 4.9, 3.1, and $0.7 \%$, respectively, of the 85,197 Anopheles specimens collected during the 1,276 paired landing catches. Allozyme studies confirmed the presence of both An. punctulatus s.s. $(n=27)$ and $A n$. koliensis $(n=118)$. The An. farauti s.l. differed electrophoretically $(n=9)$ and by DNA probe analysis $(n=127)$ from $A n$. farauti sibling species Numbers 1, 2, and 3, but a positive identification of these mosquitoes was not obtained.

The ratios of numbers of landing mosquitoes caught indoors/outdoors are given in Table 2. All these ratios differed significantly from 1:1 except for that of An. karwari $\left(\chi^{2}=2.2, P>0.05\right)$.

Spatial Pattern. Table 3 gives mean human landing rates by village for each anopheline species, for the houses and time periods sampled. There were substantial differences in both species composition and abundance (numbers relative to a collector) among villages. These averages did not allow for imbalances in the sampling effort, nor did they indicate the extent of variation within the villages. However, Fig. 3 shows contour maps of the indoor bites per person per night, averaged over

Table 2. Comparison of anopheline species

\begin{tabular}{lcccccc}
\hline \hline & An. punctulatus & An. koliensis & An. kaniari & An. farauti s.l. An. bancroftii An. longirostris \\
\hline Total caught & 31,263 & 34,376 & 12,162 & 4,156 & 611 & 2,629 \\
In/out ratio & 0.87 & 0.95 & 0.96 & 0.72 & 0.69 & 0.65 \\
Total tested for human blood & 926 & 2,097 & 313 & 111 & 38 & 31 \\
Human blood index & 0.90 & 0.79 & 0.79 & 0.88 & 0.40 & 0.84 \\
Empirical variance of CAR model estimates & 1.42 & & & & & \\
House effects $\left(\psi_{i}\right)^{a}$ & 1.00 & 5.60 & 3.49 & 2.42 & 2.90 & 2.03 \\
Night effects $\left(\theta_{j}\right)^{-1.57}$ & & 2.99 & 1.00 & 0.54 & 1.67 \\
\hline
\end{tabular}

CAR, conditional autoregression.

"Isolated groups of houses in which the species did not occur are not included in this analysis. 
Table 3. Human landing rates by village and species

\begin{tabular}{|c|c|c|c|c|c|c|c|c|}
\hline Village & $\begin{array}{l}\text { Person- } \\
\text { nights }\end{array}$ & $\begin{array}{c}\text { An. } \\
\text { punctulatus }\end{array}$ & $\begin{array}{c}\text { An. } \\
\text { koliensis }\end{array}$ & $\begin{array}{c}\text { An. } \\
\text { karuari }\end{array}$ & $\begin{array}{c}\text { An. } \\
\text { farauti s.l. }\end{array}$ & $\begin{array}{c}\text { An. } \\
\text { bancroftii }\end{array}$ & $\begin{array}{c}\text { An. } \\
\text { longirostris }\end{array}$ & Totals \\
\hline Kamge & 280 & 3.1 & 1.8 & 0.2 & 1.8 & 0.3 & 4.8 & 12.0 \\
\hline Nindigo & 260 & 3.9 & 10.1 & 0.6 & 2.0 & 0.3 & 1.5 & 18.4 \\
\hline Nale- $\ddot{2}$ & 174 & 4.1 & 14.6 & 11.7 & 7.4 & 0.5 & 2.0 & 40.3 \\
\hline Nale-1 & 300 & 5.6 & 15.0 & 26.0 & 1.8 & 0.4 & 0.3 & 49.1 \\
\hline Kunjingini-1 & 298 & 9.6 & 9.9 & 2.8 & 0.9 & 0.2 & 0.5 & 23.9 \\
\hline Nainda & 216 & 11.4 & 11.5 & 0.7 & 1.0 & 0.1 & 0.3 & 25.0 \\
\hline Katusagu & 252 & 11.6 & 2.7 & 0.6 & 1.4 & 0.3 & 0.4 & 17.0 \\
\hline Mul & 180 & 14.7 & 20.0 & 0.5 & 1.0 & 0.2 & 0.1 & 36.5 \\
\hline Apusit & $339^{a}$ & 23.1 & 23.2 & 2.2 & 0.4 & 0.1 & 0.2 & 49.2 \\
\hline Kunjingini-2 & 252 & 32.8 & 26.3 & 0.5 & 0.5 & 0.1 & 0.2 & 60.4 \\
\hline
\end{tabular}

Data tabulated are the mean numbers of mosquitoes captured from 1800 to 0600 hours per exposed mosquito collector per night over all sampling nights. Both indoor and outdoor catches are included.

a One night's sampling from Apusit consisted of indoor landing data only.

time and smoothed in space, allowing appropriately for imbalances in the sampling scheme using the conditional auto regression models. The models included data for 164 nights of sampling, in which 564 houses were represented and a total of 1,141 landing catches made.

Substantial variation in anopheline abundance was evident even within the villages, and because the peripheries of 4 villages (Kunjingini-1, Mul, Kunjingini-2, Apusit, Nindigo, and Nainda) were more or less contiguous, the spatial patterns often did not segregate by village boundaries (Fig. 3). The variances of the distributions of $\Psi_{i}$ (Table 2) measure the overall spatial variability of each species. All species had focal distributions within the study area. Although An. koliensis had the highest variance of $\Psi_{i}$, the spatial distributions of the 2 most abundant species were quite similar, with both An. punctulatus and An. koliensis abundance concentrated along the banks of the Amugu river and its tributaries in Apusit, Mul, and Kunjingini-2 (Fig. 3). An. karwari was most frequently collected in Nale village but also was relatively abundant in the parts of Apusit and Kunjingini which were nearest to Nale (and hence farthest from the Amugu river). An. farauti s.l. showed a non-overlapping distribution with An. punctulatus (Fig. 3) with relatively high densities in Nale-2 and Nindigo and low densities in Apusit, especially near the river. Although An. longirostris was relatively and infrequently collected in most villages, it was the commonest human biter in Kamge village, which formed an isolated group of houses where the other species were least abundant. It also was collected relatively frequently in the other villages along the western fringe of the study area and in Nale-2. The distribution of $A n$. bancroftii was similar to that of An. longirostris, although it was not abundant.

Changes in Landing Rates over Time. Fig. 4 shows the average mosquito abundance in the sampled houses predicted from the conditional auto regression model for each day of sampling, which comprised 8,61, 50, and $45 \mathrm{~d}$ in 1990, 1991, 1992, and 1993, respectively. Similar patterns were observed for the unadjusted geometric mean densities (not shown). Ranges of $\exp \left(\Theta_{j}\right)$ were $0.1-$ 70.27 females per person per night for An. koliensis (Fig. 4A), 0.25-26.09 for An. punctulatus (Fig. 4A), 0.02-33.82 for An. karwari (Fig. 4B), 0.075.75 for An. farauti s.l. (Fig. 4B), 0.02-4.82 for An. longirostris (Fig. 4C) and 0.04-1.52 for An. bancrofti (Fig. 4C). The variances of the night effects of $\Theta_{i}$ (Table 2) give measures of the overall temporal variability for each species. The magnitude of maximum and minimum peaks in landing rates showed that An. koliensis (Fig. 4A), An. karwari (Fig. 4B), and An. longirostris (Fig. 4C) have the highest degree of variability over time. There was much less temporal variability in landing rates of An. punctulatus (Fig. 4A), An. farauti s.l. (Fig. 4B) and $A n$. bancroftii (Fig. 4C).

The abundance of all 6 anopheline species increased following increases in rainfall (compare Fig. $4 \mathrm{~A}-\mathrm{C}$ and Fig. 4D), but there were no regular annual cycles in abundance over time. Spearman correlation coefficients between values of $\Theta_{j}$ and mean daily rainfall measured during the $4 \mathrm{wk}$ preceding day $j$ were similar for each of the 6 species, ranging from +0.18 (An. karwari) to +0.34 (An. koliensis) (all $P<0.03$ ).

Biting Cycles. Fig. 5 shows the biting cycles for each species. In each case, the percentage of human landing per hour was plotted separately for indoor and outdoor collections. An. punctulatus, An. koliensis, and An. karwari showed peak biting during the early hours of the morning, whereas $A n$. farauti s.l. and An. longirostris were abundant early in the evening (Fig. 5). The biting activity of $A n$. bancroftii occurred more or less equally throughout the night. An farauti s.l., An. longirostris, and An. bancroftii all showed a slight tendency to bite earlier outdoors than indoors.

Human Blood Index.In total, 8,463 anophelines were obtained from indoor and outdoor resting collections in the 10 villages during 1990-1993. The specimens processed for blood meal identification comprised $95.4 \%$ of all 3,685 engorged females. Of the 3,516 specimens processed, 2,245 (46.3\%) were collected resting inside houses and 


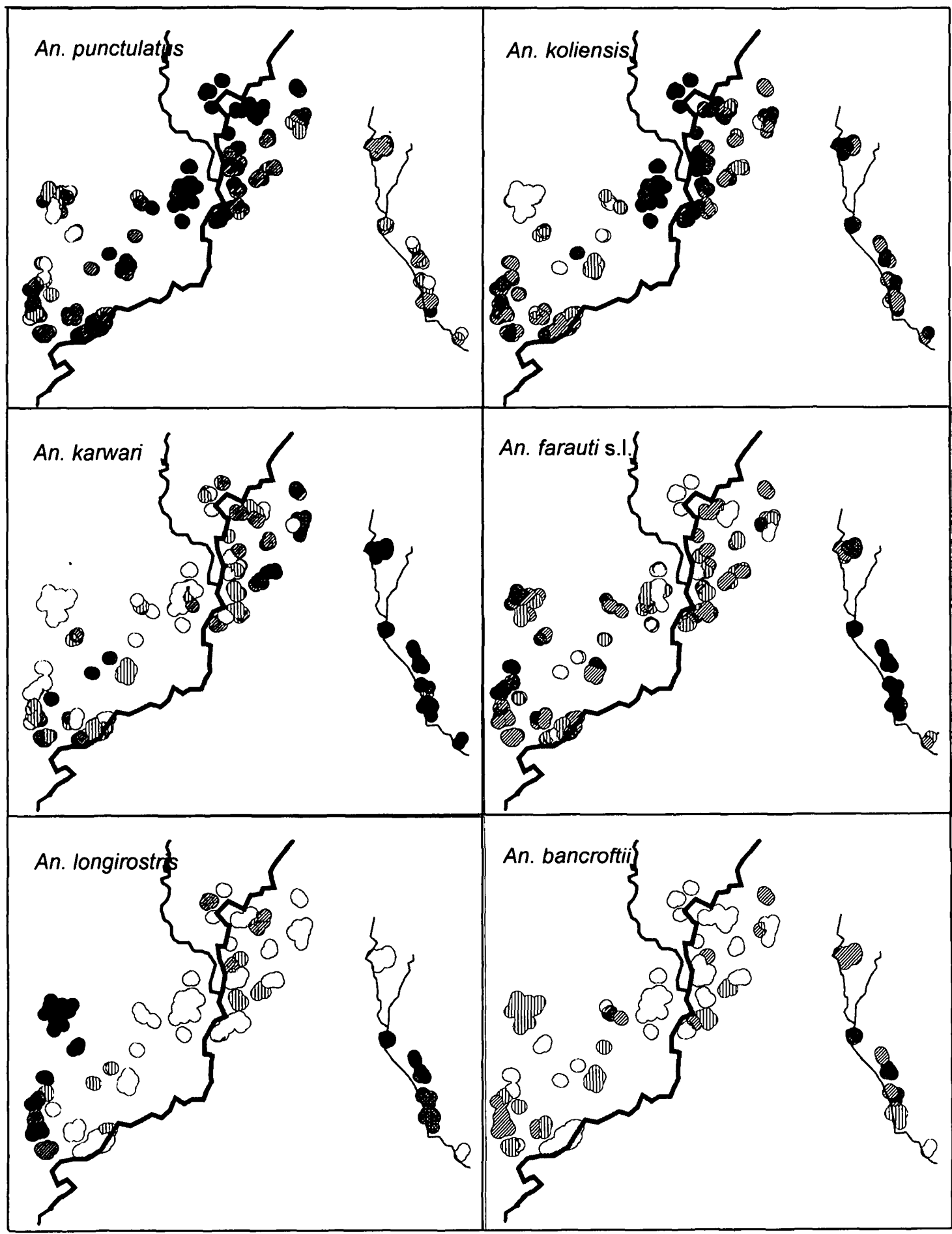

Fig. 3. Contour plot of average indoor anopheline abundance per house in Wosera during 1990-1993. Human landing rate of $A n$. punctulatus and An. koliensis: $\square,\langle 1 ; \square, 1-2 ; \square, 2-5 ; 0,5-10 ; \square,>10$. Human landing rate of An. karuari, An. farauti s.l., An. longirostris and An. bancroftii: $\square,<0.1 ; 0,0.1-0.2 ; \square, 0.2-0.5 ; 0,0.5-1.0 ; \mathbf{0},>1.0$. 

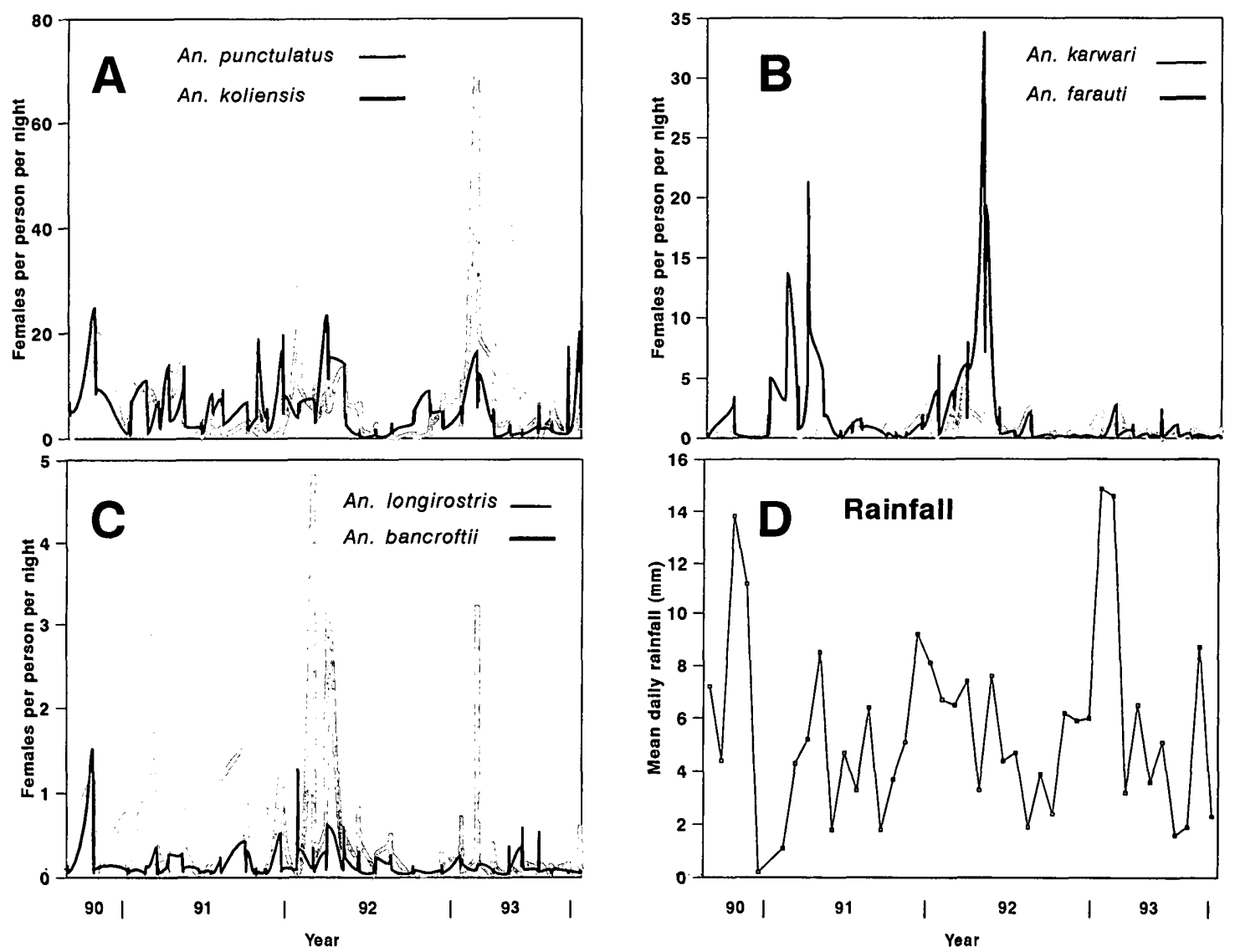

Fig. 4. Human-biting rate $\left(\exp \left(\Theta_{\mathrm{j}}\right)\right)$ of Anopheles mosquitoes estimated from indoor landing catches, $1990-1993$. Fitted values estimated from the CAR model for the 564 sampled houses. Solid lines refer to the 1st species, the dotted line to the 2nd species. (A) An. punctulatus and An. koliensis. (B) An. karvari and An. farauti s.l. (C) An. longirostris and An. bancroftii. (D) Rainfall, by 4-wk period recorded at Kunjingini, 1990-1993.

$1,271(35.1 \%)$ were collected from outdoor natural shelters. The human blood index was calculated as the sum of indoor and outdoor numbers containing a specific host blood meal divided by the total numbers of indoor and outdoor blood-fed mosquitoes (Garrett-Jones 1964). An. punctulatus had the highest HBI (Table 2) followed by An. farauti s.l., An. longirostris, An. koliensis, and An. karwari. An. bancroftii had a much lower HBI than the other species. Human blood indices calculated separately from indoor and outdoor resting mosquitoes for all species other than An. koliensis were not significantly different. $84.1 \%$ of 1,337 An. koliensis caught indoors had fed on humans, compared with $70.1 \%$ of 760 caught outdoors $\left(\chi^{2}=57.5, P<\right.$ 0.0001 ).

Index of Association Between Species. Indices of association between species reflected spatial and temporal co-occurence. The strongest positive associations were between An. punctulatus and An. koliensis (+0.85), followed by An. farauti s.l. and An. longirostris (+0.44) and An. koliensis and An. karwari (+0.34) (Table 4). An. punctulatus and An. koliensis were strongly negatively associated with the rarer species $A n$. bancroftii and An. longirostris. The negative association between An. punctulatus and An. farauti s.l. was not as obvious here as shown in Fig. 3, presumably because the tendency for them to occur in different villages was somewhat offset by a tendency to occur on the same nights.

Relationship of Numbers of Mosquitos Caught to House Construction. The quantity $\Psi_{i}-\Psi_{-x, y}$ is a measure of the deviation of mosquito abundance in house $i$ from that expected for its location. Means of $\Psi_{i}-\Psi_{-x, y}$ were computed for each anopheline species separately for houses raised on stilts (104 houses) and for houses at ground level (252 houses). The form of construction of the remaining sampled houses had not been recorded. For all 6 species differences were small and not statistically significant.

\section{Discussion}

The 6 morphological species of Anopheles identified in the Wosera area of Papua New Guinea exhibited substantial differences in abundance, 


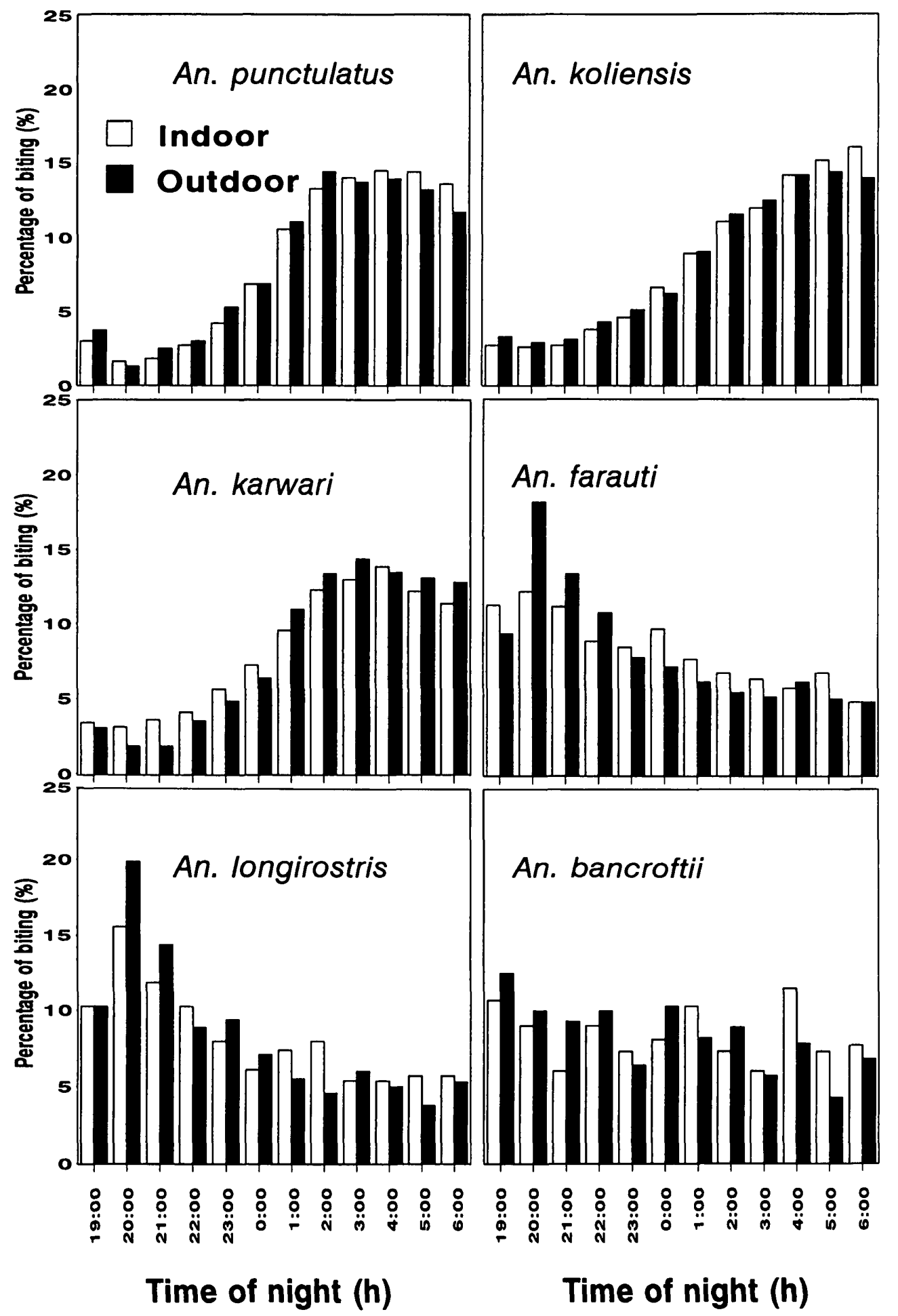

Fig. 5. Nocturnal indoor and outdoor biting cycles of females of 6 Anopheles species collected from 10 villages in study area. Open bars refer to indoor biting, and filled bars to outdoor biting. An. punctulatus ( $n=14,505$ indoor, 16,758 outdoor); An. koliensis ( $n=16,748$ indoor, 17,629 outdoor); An. karvari ( $n=5,965$ indoor, 6,197 outdoor); An. farauti s.l. ( $n=1,745$ indoor, 2,411 outdoor); An. longirostris ( $n=1,038$ indoor, 1,591 outdoor); An. bancroftii ( $n=249$ indoor, 362 outdoor). 
Table 4. Measure of association (I) between Anopheles species

\begin{tabular}{|c|c|c|c|c|c|}
\hline Species & An. koliensis & An. karvari & An. farauti s.l. & An. bancroftii & An. longirostris \\
\hline An. punctulatus & 0.85 & 0.12 & -0.27 & -0.73 & -060 \\
\hline An. koliensis & - & 0.34 & -0.09 & -068 & -0.06 \\
\hline An: karviari & - & - & 0.29 & -0.22 & -0.43 \\
\hline An. farauti s.l. & - & - & - & -0.25 & 0.44 \\
\hline An. bancroftii & - & - & - & - & -0.13 \\
\hline
\end{tabular}

spatial and temporal distribution, and biting behavior. The taxonomy of these anophelines, especially of An. farauti s.l., is not fully resolved. Foley et al. (1993) recognized 6 species of the An. farauti complex in Papua New Guinea and the Solomon Islands, but new species continue to be discovered (e.g., Foley et al. 1995).

Recently described species included one sibling morphologically identical to An. punctulatus found near the south coast of Papua New Guinea (Foley et al. 1995). However, allozyme studies indicated that the Wosera populations belong to An. punctulatus s.s. The allozyme analyses also confirmed the identity of An. koliensis from Wosera, but we cannot exclude the possibility that some An. farauti No. 4 also may occur, because this taxon is morphologically indistinguishable from An. koliensis (Foley et al. 1993). The human blood indices for An. punctulatus and An. koliensis in our study were in good agreement with those of Burkot et al. (1988a) for the Madang area.

The abundance of An. punctulatus was highest along the low-lying banks of the Amugu River and adjacent tracts of sago swamp running north-south through Apusit, Kunjingini-1, Kunjingini-2, and $\mathrm{Mul}$, but with its abundance decreasing with distance from the river. Because the fringes of the river are populated densely and have the most intensive agriculture, this is consistent with a high degree of vector anthropophily and with An. punctulatus breeding in the areas most disturbed by human activity. Although this species has been reported to disperse up to $1.8 \mathrm{~km}$ from a release site (Charlwood and Bryan 1987), most females remained concentrated in small areas along the banks of the Amugu River, most noticeably in Apusit and Kunjingini-2.

Although An. koliensis reportedly exploits larval habitats different than those of An. punctulatus (Charlwood et al. 1986, Lee et al. 1987), we found that adults of the 2 species were strongly associated, even though An. koliensis showed more variation over time in landing catches and showed a decreasing gradient of abundance away from the Amugu (Screw) River. Larvae of An. koliensis were collected from the sago swamps among the northerly hamlets of Apusit and Kunjingini-1, which may have been major breeding sites (unpublished data), but we do not have an explanation for the relative scarcity of this species in areas around similar swamps near Kamge and Nainda. Larvae occasionally have been found in temporary habitats at the forest margin (Owen 1945, Belkin 1962).
Peters and Standfast (1960) also found An. koliensis to be more seasonal than An. punctulatus in the same area as the current study, whereas changes in population density of both species were synchronized with monthly rainfall in the Madang area (Charlwood 1985, Burkot et al. 1988b).

Landing rates of An. farauti s.l. were highly seasonal near Madang (Afifi et al. 1980, Charlwood et al. 1986, Burkot et al. 1988b), and in that area it was the predominant vector of malaria in coastal but not inland villages, breeding mainly in coastal streams with large temporal fluctuations in adult densities. Although not as early as in the Wosera, peak landing catches in Madang area also occurred before midnight (Charlwood 1985). In the Wosera, An. farauti s.l. was one of the species with the least variation over time in landing catches and has a relatively early biting cycle, in agreement with the previous study of Standfast (1967) from the Maprik district. The human blood index in our study was double that of coastal An. farauti s.l. reported by Burkot et al. (1988a). It occured mostly in the villages of Nale-1 and Nale-2, but even there peak abundance was not high. This species seems to be associated with less disturbed habitats than those of An. punctulatus, and the Imperata spp. grassland would seem to provide some degree of isolation from the anopheline communities in the center of the study area. Allozyme and DNA probe results (D. Foley and N. Beebe, personal communication) indicated that the An. farauti s.l. in Wosera is a different species than the coastal populations which belong to An. farauti No. 1 .

The morphotype of An. longirostris also may consist of several sibling species in Papua New Guinea (D. Foley, personal communication). Unlike Charlwood et al. (1985), we found An. longirostris to be predominantly anthropophagic; therefore we suspect that another sibling species different from that in Madang may predominate in Wosera. There is a relatively high abundance of An. longirostris, both in Kamge at the western side of the study area where this species accounts for the most human biting, and in Nale-2.

Anopheles karwari, which can be identified easily morphologically, breeds in foothill seepages and small streams (Lee et al. 1987) but has a spatial distribution in Wosera similar to that of An. farauti s.l. and is concentrated in Nale-1 and Nale-2, perhaps breeding in the small creeks there. In Nale1, An. karwari is the most abdundant anopheline biting humans. An. karwari showed much more temporal variation in abundance than did An. far- 
auti s.l.; therefore, despite similar spatial distributions, we suspect that these species have different breeding sites.

The least abundant anopheline recorded, An. bancroftii also can be identified morphologically. It showed less temporal variation in abundance than the other species and is the least anthropophagic, occurring at low densities in all the villages. This species also has a low propensity for human biting in Australia, preferring to feed on domestic animals (Lee et al. 1987).

It has long been recognized (Peters and Standfast 1960) that the most intense malaria transmission in Papua New Guinea occurs where the main vectors are An. punctulatus or An. koliensis. The high human blood indices of these species are an important reason for this, but none of the Papua New Guinea species fed exclusively on humans. An. koliensis fed on marsupials and pigs as well as on humans, and An. punctulatus also fed on pigs (Foley et al. 1993). The late-biting cycles of these 2 most frequently collected species may be a specialization for human biting which they share with Afrotropical malaria vectors (Charlwood et al. 1996). However An. karwari also has a late-biting cycle, although it prefers to feed on bovines in Asia (Lee et al. 1987). Cattle are not found in Wosera where An. karwari has a high human blood index. In Nale-1, it was the anopheline with the highest human landing rate; therefore, it may be an important malaria vector in this area.

Because the more abundant anophelines tend to occur together in time and space, there is marked spatial clustering of human biting in Wosera. It may be that the clustering of malaria transmission is even more pronounced, because the minor anopheline species, whose spatial distributions to some extent complement those of the more abundant species, probably are less efficient vectors. An. farauti s.l., An. longirostris, and An. bancroftii are early outdoor biters and seem to be more successful in biting people that are engaged in outdoor activities before midnight. However, because they are less likely to enter houses, this would make it easier for people to avoid them. Nevertheless, all these species except An. bancroftii had high human blood indices; therefore, their importance as vectors of malaria remains uncertain.

It seems unlikely that human behavior plays an important role in either spatial or temporal variation in landing rates. Although there are large differences among villages in the use of mosquito bed nets (Genton et al. 1994), these nets are not impregnated with insecticide. The structure of houses and the activity patterns and life styles of the people varied little among the villages. Only the mission station at Kunjingini-1 formed a discrete area of houses, some of which were screened against mosquitoes. In contrast to the study by Charlwood et al. (1984) in coastal Madang of Papua New Guinea, we did not find a significant reduction in landing rates in raised structures, presumably be- cause different sibling species of An. farauti occurred there.

The evidence presented here clearly shows that Anopheles populations are clustered rather than homogeneously distributed, although explanations for these patterns are not clear. The co-occurence of An. punctulatus and An. koliensis in Wosera, despite focal distributions of both species, may lead to extreme variation in space in the transmission of malaria. The degree of concentration of anopheline abundance in Wosera might be exceptional, but given the degree of species diversity (Foley et al. 1993) and breeding site specialization (Charlwood 1985, Charlwood et al. 1986), extreme small-area variation in the composition of anopheline communities is probably a general characteristic in Papua New Guinea. The consequent large variations in malaria transmission over a few hundreds of meters very likely play an important role in keeping some parts of the human population relatively free from sporozoite inoculations and reducing the spread of Plasmodium variants. It also may explain the small-area epidemiological variations observed by Cattani et al. (1986b). Further analyses of our data will consider the sporozoite rates in the different anopheline species. This will make possible a direct test of this hypothesis by relating malaria in the human population to measured entomological inoculation rates.

\section{Acknowledgments}

We thank M. Packer, R. Paru, E. Ibam, H. J)agoro, E. Renyard, M. Lagog, M. Baea, L. Rare, J. Taime, P. Kave, and D. Kotale for excellent technical and logistic support. We are grateful to J. D. Charlwood, R. D. (Cooper, I). Foley, and J. H. Bryan for their helpful comments on the manuscript. D. Foley and N. Beebe are thanked for identifying specimens using electrophoresis and 1)NA species-specific probes. We thank an anonymous reviewer and W. Reisen for valuable suggestions. We thank the members of the field teams in Wosera, as well as villagers among the 10 communities, for their cooperation and active participation. Clearance for this research was given by the Medical Research Advisory Committee of Papua New Guinea. This work was part of the Malaria Vaccine Epidemiology and Evaluation Project funded by the United States Agency for International Development No. 9365967.89. Data analysis was partly supported by Swiss National Science Foundation Grant No. 32-43427.95.

\section{References Cited}

Afifi, A., M. Spencer, P. B. Hudson, and N. W. Tavil. 1980. Biting prevalence and malaria transmission patterns in the Anopheles punctulatus complex (J)iptera: Culicidae) in Papua New Guinea. Aust. J. Exp. Biol. Med. Sci. 58: 1-17.

Allen B. J., R. L. Hide, D. Bourke, D. Fritsch, R. Grau, E. Lowes, T. Nen, E. Nirsie, J. Risimeri, and M. Woruba. 1993. Agricultural systems of Papua New Guinea, working paper No. 2. East Sepik Province: text summaries, maps, code lists and village Identification. ANU, Canberra. 
Alpers, M. P., F. Al-Yaman, H.-P. Beck, K. K. Bhatia, J. Hii, D. J. Lewis, R. Paru, and T. Smith. 1992. The malaria vaccine epidemiology and evaluation project of Papua New Guinea: rationale and baseline studies. P.N.G. Med. J. 35: 285-297.

Beier, J. C., P. V. Perkins, R. A. Wirtz, J. Koros, D. Diggs, T. P. Gargan, and D. K. Koech. 1988. Bloodmeal identification by direct enzyme-linked immunosorbent assay (ELISA), tested on Anopheles (Diptera: Culicidae) in Kenya. J. Med. Entomol. 25: 9-16.

Belkin, J. N. 1962. The mosquitoes of the South Pacific (Diptera: Culicidae), vols. 1 and 2. University of California Press, Berkeley.

Burkot, T. R., P. M. Graves, J. A. Cattani, R. A. Wirtz, and F. D. Gibson. 1987. The efficiency of sporozoite transmission in the human malarias, Plasmodium falciparum and P. vivax. Bull. W.H.O. 65: 375-380.

Burkot, T. R., P. M. Graves, R. Paru, and M. Lagog. 1988a. Mixed bloodfeeding by the malaria vectors in the Anopheles punctulatus complex (Diptera: $\mathrm{Cu}$ licidae). J. Med. Entomol. 25: 205-213.

Burkot, T. R., P. M. Graves, R. Paru, R. A. Wirtz, and $P$. F. Heywood. 1988b. Human malaria transmission studies in the Anopheles punctulatus complex in Papua New Guinea: sporozoite rates, inoculation rates and sporozoite densities. Am. J. Trop. Med. Hyg. 39: 135-144.

Cattani, J. A., J. L. Tulloch, H. Vrbova, D. Jolley, F. D. Gibson, J. S. Moir, P. F. Heywood, M. P. Alpers, A. Stevenson, and R. Clancy. 1986a. The epidemiology of malaria in a population surrounding Madang, Papua New Guinea. Am. J. Trop. Med. Hyg. 35: 3-15.

Cattani, J. A., J. S. Moir, F. D. Gibson, M. Ginny, J. Paino, W. Davidson, and M. P. Alpers. $1986 \mathrm{~b}$. Small-area variations in the epidemiology of malaria in Madang Province. P.N.G. Med. J. 29: 11-17.

Charlwood, J. D., R. Paru, H. Dagoro, M. Lagog, L. Kelepak, S. Yabu, P. Krimbo, and P. Pirou. 1983. Factors affecting the assessment of man biting rates of malaria vectors, pp. 143-151. In J. H. Bryan and P. M. Moodie [eds.], Malaria: proceedings of a conference to honour Robert H. Black. Australian Government Publishing Service, Canberra.

Charlwood, J. D., R. Paru, and H. Dagoro. 1984. Raised platforms reduce mosquito bites. Trans. R. Soc. Trop. Med. Hyg. 78: 141-142.

Charlwood, J. D. 1985. The influence of larval habitat on the ecology and behavior of females of the punctulatus group of Anopheles mosquitoes from Papua New Guinea, pp. 399-406. In L. P. Lounibos, I. R. Rey, and J. H. Frank [eds.], Ecology of mosquitoes: proceedings of a workshop. Florida Medical Entomology Laboratory, Vero Beach.

Charlwood, J. D., H. Dagoro, and R. Paru. 1985. Blood feeding and resting behaviour in the Anopheles punctulatus group (Diptera: Culicidae) from Madang. Bull. Entomol. Res. 75: 463-475.

Charlwood, J. D., P. M. Graves, and M. P. Alpers. 1986. The ecology of the Anopheles punctulatus group of mosquitoes from Papua New Guinea: a review of recent work. P.N.G. Med. J. 29: 19-26.

Charlwood, J. D., and J. H. Bryan. 1987. A markrecapture experiment with the filariasis vector Anopheles punctulatus in Papua New Guinea. Ann. Trop. Med. Parasitol. 81: 429-436.
Charlwood, J. D., P. M. Graves, and T. F. de C. Marshall. 1988. Evidence for a memorised home range in Anopheles farauti. Med. Vet. Entomol. 2: 101-108.

Charlwood, J. D., T. Smith, J. Kihonda, P. F. Billingsley, and W. Takken. 1996. Density independent feeding success in malaria vectors from Tanzania. Bull. Entomol. Res. 85: 29-35.

Cooper, L., R. D. Cooper and T. R. Burkot. 1991 The Anopheles punctulatus complex: DNA probes for identifying the Australian species using isotopic, chromogenic and chemiluminescence detection systems. Exp. Parasitol. 73: 27-35.

Dye, C., and G. Hasibeder. 1986. Population dynamics of mosquito-bome diseases: effects of flies which bite some people more frequently than others. Trans. R. Soc. Trop. Med. Hyg. 80: 69-77.

Foley, D. H., R. Paru, H. Dagoro, and J. H. Bryan. 1993. Allozyme analysis reveals six species within the Anopheles punctulatus complex of mosquitoes in $\mathrm{Pa}-$ pua New Guinea. Med. Vet. Entomol. 7: 37-48.

Foley, D. H., R. D. Cooper, and J. H. Bryan. 1995. A new species within the Anopheles punctulatus complex in Westem Province, Papua New Guinea. J. Am. Mosq. Control Assoc. 11: 122-127.

Forsyth, K. P., R. F. Anders, J. A. Cattani, and M. P. Alpers. 1989. Small area variation in prevalence of an S-antigen serotype of Plasmodium falciparum in villages of Madang, Papua New Guinea. Am. J. Trop. Med. Hyg. 40: 344-350.

Garrett-Jones, C. 1964. The human blood index of malaria vectors inrelation to epidemiological assessment. Bull. W.H.O. 30: 241-261.

Genton, B., J. Hii, F. Al-Yaman, R. Paru, H.-P. Beck, M. Ginny, H. Dagoro, D. Lewis, and M. P. Alpers. 1994. The use of untreated bednets and malaria infection, morbidity and immunity. Ann. Trop. Med. Parasitol. 88: 263-270.

Genton B., F. Al-Yaman, H.-P. Beck, J. Hii, S. Mellor, A. Narara, N. Gibson, T. Smith, and M. P. Alpers. 1995. The epidemiology of malaria in the Wosera area, East Sepik Province of Papua New Guinea, in preparation for vaccine trials. I. Malariometric indices and immunity. Ann. Trop. Med. Parasitol. 89: 359376.

Greenwood, B. M. 1989. The microepidemiology of malaria and itsimportance to malaria control. Trans. R. Soc. Trop. Med. Hyg. 83: 25-29.

Haanjens H. A., J. M. Arnold, J. R. McAlpine, J. A. Mabbutt, E. Reiner, R. G. Robbins, and J. C. Saunders. 1968. Lands of the Wewak-Lower Sepik Area, Territory of Papua New Guinea. Land Research Series No. 22, CSIRO, Melbourne.

Lee D. J., M. M. Hicks, M. Griffiths, M. L. Debenham, J. H. Bryan, R. C. Russell, M. Geary, and E. N. Marks. 1987. The Culicidae of the Australasian Region, vol. 5. Australian Government Publishing Service, Canberra.

MapInfo. 1990. MapInfo, version 1.1. MapInfo, Troy, NY.

Metselaar, D. 1957. A pilot project of residual insecticide spraying in Netherlands New Guinea, contribution to the knowledge of holo-endemic malaria. Acta Leiden. 27: 1-128.

Nakazawa M., R. Ohtsuka, T. Kawabe, T. Hongo, T. Suzuki, T. Inaoka, T. Akimichi, S. Kano, and M. Suzuki. 1994. Differential malaria prevalence among villages of the Gidra in lowland Papua New Guinea. Trop. Geogr. Med. 46: 350-354. 
Owen, W. B. 1945. A new anopheline from the Solomon islands with notes on its biology. J. Parasitol. 31: $236-240$.

Peters, W. 1960a. Studies on the epidemiology of malaria in New Guinea. I. Holoendemic malaria-the clinical picture. Trans. R. Soc. Trop. Med. Hyg. 54: 242-248.

1960b. Studies on the epidemiology of malaria in New Guinea. III. Holoendemic malaria-the analysis of data and relation to control. Trans. R. Soc. Trop. Med. Hyg. 54: 254-260.

1965. Ecological factors limiting the extension of malaria in the southwest Pacific-their bearing on malaria control or eradication programmes. Acta Trop. 22: 62-69.

Peters, W., and H. A. Standfast. 1960. Studies on the epidemiology of malaria in New Guinea. II. Holoendemic malaria-the entomological picture. Trans. R. Soc. Trop. Med. Hyg. 54: 249-254.

Peters, W., and S. H. Christian. 1963. The bionomics, ecology anddistribution of some mosquitoes (Diptera: (ulicidae) in the Territory of Papua and New Guinea. Acta Trop. 20: 35-79.

Rook, H. de 1929. Malaria en anophelinen aan de Boven-Digoel. Rapport D.V.G., Batavia, Indonesia.
Service, M. 1993. Indices of association between species and species diversity, pp. 890-913. In M. W. Service [ed.], Mosquito ecology: field sampling methods, 2nd ed. Elsevier, London.

Smith T., J. D. Charlwood, W. Takken, M. Tanner, and D. Spiegelhalter. 1995. Mapping the densities of malaria vectors within a single village. Acta Trop. 59: $1-18$.

Southwood, T.R.E. 1978. Ecological methods with particular reference to the study of insect populations. Chapman \& Hall, London.

Spencer, M. 1970. Density and longevity of Anopheles farauti Laveran. P.N.G. Med. J. 13: 84-90.

Standfast, H. A. 1967. Biting times of nine species of New Guinea Culicidae (Diptera). J. Med. Entomol. 4: 192-196.

Thomas, A., D. J. Spiegelhalter, and W. R. Gilks. 1992. BUGS: a program to perform Bayesian inference using Gibbs sampling, pp. 837-842. In J. M Bernado, J. O. Berger, A. P. Dawid, and A.F.M. Smith [eds.], Bayesian statistics, vol. 4. Clarendon, Oxford.

Received for publication 7 March 1996; accepted 26 September 1996. 